\title{
Article
}

\section{A Novel Natural GRAS-Grade Enteric Coating for Pharmaceutical and Nutraceutical products}

Khoder, Mouhamad, Schropp, Verena, Zeitler, Susanne, Pereira, Beatriz, Habashy, Rober, Royall, Paul G., Tzu-Wen Wang, Julie and Alhnan, Mohamed A

Available at http://clok.uclan.ac.uk/33234/

Khoder, Mouhamad, Schropp, Verena, Zeitler, Susanne, Pereira, Beatriz, Habashy, Rober, Royall, Paul G., Tzu-Wen Wang, Julie and Alhnan, Mohamed A (2020) A Novel Natural GRAS-Grade Enteric Coating for Pharmaceutical and Nutraceutical products. International Journal of Pharmaceutics, 584 . p. 119392. ISSN 0378-5173

It is advisable to refer to the publisher's version if you intend to cite from the work. http://dx.doi.org/10.1016/j.ijpharm.2020.119392

For more information about UCLan's research in this area go to

http://www.uclan.ac.uk/researchgroups/ and search for <name of research Group>.

For information about Research generally at UCLan please go to http://www.uclan.ac.uk/research/

All outputs in CLoK are protected by Intellectual Property Rights law, including Copyright law. Copyright, IPR and Moral Rights for the works on this site are retained by the individual authors and/or other copyright owners. Terms and conditions for use of this material are defined in the policies page. 


\section{Journal Pre-proofs}

A Novel Natural GRAS-Grade Enteric Coating for Pharmaceutical and Nutraceutical products

Mouhamad Khoder, Verena Schropp, Susanne Zeitler, Beatriz Pereira, Rober Habashy, Paul G. Royall, Julie Tzu-Wen Wang, Mohamed A Alhnan

PII: S0378-5173(20)30376-8

DOI: https://doi.org/10.1016/j.ijpharm.2020.119392

Reference: IJP 119392

To appear in:

International Journal of Pharmaceutics

Received Date:

2 November 2019

Revised Date:

27 April 2020

Accepted Date:

28 April 2020

Please cite this article as: M. Khoder, V. Schropp, S. Zeitler, B. Pereira, R. Habashy, P.G. Royall, J. Tzu-Wen Wang, M.A. Alhnan, A Novel Natural GRAS-Grade Enteric Coating for Pharmaceutical and Nutraceutical products, International Journal of Pharmaceutics (2020), doi: https://doi.org/10.1016/j.ijpharm.2020.119392

This is a PDF file of an article that has undergone enhancements after acceptance, such as the addition of a cover page and metadata, and formatting for readability, but it is not yet the definitive version of record. This version will undergo additional copyediting, typesetting and review before it is published in its final form, but we are providing this version to give early visibility of the article. Please note that, during the production process, errors may be discovered which could affect the content, and all legal disclaimers that apply to the journal pertain.

(C) 2020 Published by Elsevier B.V. 


\section{Nutraceutical products}

Mouhamad Khoder ${ }^{\mathrm{a}}$, Verena Schropp ${ }^{\mathrm{b}, \mathrm{c}}$, Susanne Zeitler ${ }^{\mathrm{c}}$, Beatriz Pereira ${ }^{\mathrm{c}}$, Rober Habashy ${ }^{\mathrm{c}}$, Paul G. Royall $^{\mathrm{d}}$, Julie Tzu-Wen Wang ${ }^{\mathrm{d}}$, Mohamed A Alhnan*d

a Drug Discovery, Delivery and Patient Care (DDDPC) Theme, School of Life Sciences, Pharmacy and Chemistry, Kingston University London, Kingston Upon Thames, London.

${ }^{b}$ Friedrich-Alexander University Erlangen-Nürnberg (FAU), Erlangen, Germany.

c School of Pharmacy and Biomedical Sciences, University of Central Lancashire, Preston PR1 2HE, United Kingdom.

d Institute of Pharmaceutical Science, King's College London, London, UK.

*Corresponding author at:

Institute of Pharmaceutical Sciences

King's College London

150 Stamford Street

London SE1 9NH. Tel.: +44 (0)207848 7265 .

Electronic address: Alhnan@kcl.ac.uk 
In this study, enteric coatings based exclusively on naturally occurring ingredients were reported. Alginate (Alg) and pectin (Pec) blends with or without naturally occurring glyceride, glycerol monostearate (GMS), were initially used to produce solvent-casted films. Incorporating GMS in the natural polymeric films significantly enhanced significantly the acid-resistance properties in gastric medium. Theophylline tablets coated with Alg-Pec blends without GMS disintegrated shortly after incubation in gastric medium ( $\mathrm{pH}$ 1.2), leading to a premature and complete release of theophylline. Interestingly, tablets coated with Alg-Pec blends that contain the natural glyceride (GMS) resisted the gastric environment for $2 \mathrm{~h}$ with minimal drug release $(<5 \%)$ and disintegrated rapidly following introduction to the intestinal medium, allowing a fast and complete drug release. Furthermore, the coating system proved to be stable for six months under accelerated conditions. These findings are particularly appealing to nutraceutical industry as they provide the foundation to produce naturally-occurring GRAS based enteric coatings with no daily intake limits.

Keywords: gastro-resistant, code oil, probiotics, delayed-release, nutraceuticals, enteric-coatings 


\section{Introduction}

Journal Pre-proofs

The global nutraceutical market is expected to grow above 500 billion USD by 2025 (Research, 2019).

A significant portion of the products in this market is enterically coated. Enteric coating has been successfully used to prevent drugs release in stomach (e.g. code oil) and to protect acid- and enzymelabile drugs from the harsh gastric acidity (e.g. enzymes or probiotics) (Martini and Crowley, 2011). Typically, $\mathrm{pH}$-dependent polymeric films are applied on the core to resist to the lower $\mathrm{pH}$ in the stomach but rapidly dissolve upon the pH increase in the duodenum (Khoder et al., 2010; Siegel and Rathbone, 2012). Synthetic polymers, such as methacrylic acid copolymers, marketed as Eudragit ${ }^{\circledR}$, and semisynthetic polysaccharides derivatives, such as cellulose acetate phthalate and hydroxypropyl methylcellulose phthalate, have been mainly used as enteric coatings (Maderuelo et al., 2019). However, these polymers are subjected to restrictions, including, but not limited to, the use of ammonium and/or organic solvents for their synthesis and applications and the lack of biodegradability. Moreover, their restricted daily limit intake poses a real challenge for the enteric coating of nutraceuticals and dietary supplements in particular (Czarnocka and Alhnan, 2015). More recently, a GRAS, generally recognized as safe (FDA) version of acrylic polymers has been recently introduced to the market (e.g. Eudraguard Biotic $\left.^{\circledR}\right)$. However, the synthetic nature of these polymers raised the question about their suitability as coatings for nutraceutical products.

Shellac is biodegradable, biocompatible, abundant, and water soluble with no daily intake limits, hence it has been considered as an attractive natural GRAS pharmaceutical excipient. Additionally, shellac has been used to lower water uptake and to improve task-masking properties of film coatings (Pearnchob et al., 2003). The use of shellac is often associated with batch-to-batch variations and slower than expected release due to its polymerisation during storage (Farag and Leopold, 2009). Regulating shellac performance has also been attempted through the use of ammoniated shellac solutions (Limmatvapirat et al., 2005), the addition of alginate (Alg) (Czarnocka and Alhnan, 2015), and the addition of alkaline middle layer in a multiple layer coating (Theismann et al., 2019). However, the resulted products suffered a slow drug release in biologically relevant dissolution tests. Many nutraceutical products are coated using commercially available GRAS-based coatings, often based on semi-synthetized cellulose 
derivatives. Disappointinglv. none of the investigated GRAS-grade coatings fullv complied with the Journal Pre-proofs

different biological demands of delayed release coating systems, i.e. $<10 \%$ release after 2 hours at $\mathrm{pH}$ 1.2 followed by $>80 \%$ release after 45 min in $\mathrm{pH} 6.8$ medium (Khoder et al., 2010).

Alginate (Alg) and pectin (Pec) are both considered as GRAS polysaccharides and have been used to coat immediate release cores (Barbosa et al., 2017; Rajsharad and Kamble, 2006) and to produce orodispersible films (Hoffmann et al., 2011). Despite their good film-forming properties, neither polysaccharide fulfils the role of a good enteric coating polymer. Indeed, although both polymers do not dissolve in an acidic medium; however, they lack the gastro-resistance barrier. This is due to their water uptake capability with the subsequent permeability and the acidic hydrolysis that they might undergo in such harsh acid conditions (Sriamornsak and Kennedy, 2008). Although chemical modification can potentially enhance the polysaccharides' gastro-resistant properties, such an approach yields new chemical entities that will defeat the purpose of crafting a naturally occurring polymer for nutraceutical products. An alternative formulation approach of employing physical blends of enteric and extended release polymers proved successful in the engineering of the desired release patterns for methacrylic acrylic and cellulosic based polymers (Lecomte et al., 2003; Lecomte et al., 2004; Siepmann et al., 2008b).

Here, we report for the first time the development of Alg and Alg-Pec based coating system that complies with the pharmacopeial criteria of enteric coating. A naturally occurring glyceride, glycerol monostearate (GMS), was incorporated into the film matrices to construct gastro-resistance barrier of the film. Initially, films made of Alg-Pec blends with or without GMS were produced by solvent casting method. The impact of incorporating with the GMS on water uptake and weight loss of the resulting films in the acid medium were assessed. GMS containing Alg-Pec blends were then applied as coating films onto core model tablets and the gastro-resistant barrier of the coating system was established according the pharmacopeial criteria for enteric coatings. 
2.1. Materials

Theophylline anhydrous was purchased from Acros organics (New Jersey, USA). Directly compressible lactose monohydrate - Ludipress was supplied by BASF SE (Germany). Polyvinylpyrrolidone (PVP) K90, magnesium stearate and sodium alginate (Alg) (grade 15-20 cps) and pectin (Pec) from citrus fruits were supplied by Sigma-Aldrich Co., Ltd. (Dorset, UK). Microcrystalline cellulose (MCC) PH 101 and crosscarmellose sodium SD-711 were provided by FMC Biopolymer (Belgium). GMS (Imwittor K900) was a generous donation of IOI Oleo GmbH (Germany). The gastric medium consisted of a $0.1 \mathrm{M}$ hydrochloric acid solution ( $\mathrm{pH} 1.2)$. The intestinal medium was made by adding $250 \mathrm{~mL}$ of $0.214 \mathrm{M}$ tribasic phosphate to the gastric medium to raise the $\mathrm{pH}$ to 6.8 .

\subsection{Preparation of films}

Mixtures (4 g) of different Alg:Pec ratios (100:0, 85:15, 70:30, 50:50, 0:100) were dissolved in $100 \mathrm{~mL}$ water at $70{ }^{\circ} \mathrm{C}$ to produce $4 \% \mathrm{w} / \mathrm{v}$ solutions. A volume of $20 \mathrm{~mL}$ of the obtained solutions was then individually poured into a Teflon coated plate $(120 \mathrm{~mm}$ diameter $)$ and left to dry at $40{ }^{\circ} \mathrm{C}$ for 3 hours in fan oven. Upon drying, the films were peeled off the plate, cut into regular squares $(15 \times 15 \mathrm{~mm})$, and stored in plastic bags for further tests. In order to assess the impact of incorporating GMS in films properties, a similar set of the above mentioned polysaccharides solutions was prepared by including $0.25 \mathrm{~g}$ GMS in the powder blends before introduction to hot water to yield a GMS: polymer ratio of 1:16. The obtained systems were kept under magnetic stirring at $70^{\circ} \mathrm{C}$ to ensure the consistent dispersion of molten GMS in the polysaccharides solutions. Films were then created following the same method mentioned above.

\subsection{Thermal Analysis}

\section{a. Differential Scanning Calorimetry (DSC)}

Samples of Alg, Pec, GMS, and Alg:Pec (85:15) cast films with or without GMS (GMS: polymers 1:16) were analysed by differential scanning calorimetry (DSC). DSC Q2000 (TA Instruments, Elstree, UK) 
was used to assess the thermal behaviour of the samples: approximatelv $5 \mathrm{mg}$ samples were scanned Journal Pre-proofs

from 0 to $180^{\circ} \mathrm{C}$ using at a heating rate of $10^{\circ} \mathrm{C} / \mathrm{min}$ and a nitrogen purge of $50 \mathrm{~mL} / \mathrm{min}$.

\section{b. Thermographic Analysis (TGA)}

TGA Q500 (TA Instruments, Elstree, Hertfordshire, UK) was used to analyse approximately $10 \mathrm{mg}$ of Alg, Pec, GMS, and Alg:Pec (85:15) cast films with or without GMS (GMS: polymers 1:16). Samples were heated at a rate of $10^{\circ} \mathrm{C} / \mathrm{min}$ from $25^{\circ} \mathrm{C}$ to $500^{\circ} \mathrm{C}$ with a nitrogen purge of $40: 60 \mathrm{~mL} / \mathrm{min}$ for sample: furnace respectively. TA Universal analysis software (version 4.5A, TA Instruments, Elstree, UK) was used to analyse data for both DSC and TGA.

\section{c. Differential Scanning Calorimetry (DSC) with digital microscopy of coating dispersion}

The DSC optical camera experiments were conducted using a TA instruments discovery 2500 (TA Instruments, Elstree, Hertfordshire, UK) and T zero aluminium pans with a heating rate of $10^{\circ} \mathrm{C} / \mathrm{min}$ under a purge gas of nitrogen. The instrument had been previously calibrated with both indium and lead. Approximately $12 \mathrm{mg}$ of the coating dispersion (GMS: polymers 1:16) was placed in a pre-marked DSC pan. The marking of a cross was applied by lightly scratching the surface of the empty DSC pan using the tip of a pair of stainless-steel tweezers. The purpose of the cross was to aid in focusing and contrasting the clarity of the dispersion during the heating cycle. Images were recorded using the TA instruments discovery DSC microscope accessory equipped with a high-resolution digital microscope camera with a 50 times magnification when focused on the DSc cell allowing a $5 \mathrm{~mm}$ field of view.

\section{d. Light microscopy of coating dispersion}

The above specified coating dispersion $\left(70^{\circ} \mathrm{C}\right)$ was tested using temperature-controlled Leica light microscope equipped with QIClick camera and the images were processed using Q-Capture Pro 7 (Teledyne Imaging, Surrey, Canada).

\subsection{Water uptake and weight loss studies of casted films}


The original weight (OW) of drv films was accuratelv measured and films were individuallv placed in Journal Pre-proofs

beakers containing $50 \mathrm{~mL}$ of gastric medium $(0.1 \mathrm{M} \mathrm{HCl})$. The beakers were then positioned in a water bath of $37^{\circ} \mathrm{C}$ and agitated at a speed of $100 \mathrm{rpm}$. At specific time intervals $(0,10,60$ and $120 \mathrm{~min})$, films were gently removed, the external moisture was removed, and the films wet weights (WW) were taken. The samples were then dried at $40{ }^{\circ} \mathrm{C}$ until no further weight variation was observed and the subsequent dry weight (DW) was noted. Different film was used at each time. The water uptake percentage by film was calculated according to Eq. 1:

$$
\text { Water uptake }(\%)=\frac{W W-D W}{D W} \times 100
$$

and the weight loss percentage was calculated according to Eq. 2:

$$
\text { Weight loss }(\%)=\frac{O W-D W}{O W} \times 100
$$

\subsection{Preparation of theophylline tablets}

Theophylline $(150 \mathrm{mg})$ tablets were used as model cores to assess the performance of coating systems. The model cores were prepared by wet granulation method formulated as previously reported (Czarnocka and Alhnan, 2015). Briefly, $250 \mathrm{~g}$ theophylline, $240 \mathrm{~g}$ lactose monohydrate, $10 \mathrm{~g}$ PVP grade K90 and $130 \mathrm{~mL}$ water were mixed for $15 \mathrm{~min}$ and granulated though $1 \mathrm{~mm}$ sieve using Erweka AR 402 granulator (Erweka, Germany). Granules were dried at $60^{\circ} \mathrm{C}$ until no weight loss was observed. Granules (500 g) were mixed with 310 g lactose monohydrate, 150 g MCC, 30 g Ac-Di-Sol and 10 g magnesium stearate and the resultant mass was compressed using a Riva Minipress single punch tableting machine (Riva, Argentina).

\subsection{Coating of theophylline tablets}

The coating formulations were prepared by dissolving $8 \mathrm{~g}$ of Alg-Pec blend (Alg:Pec 85:15) without or with the addition of 0.5 GMS (GMS:polymers 1:18) or 0.5 g PEG 6000 (PEG:polymers 1:18) in 400 $\mathrm{mL}$ of water that was heated at approximately $70{ }^{\circ} \mathrm{C}$ under cover during coating process. The resultant coating liquids were applied to theophylline tablets (batch size $30 \mathrm{~g}$ ) using a Strea-1 bottom spray fluidised bed coater (GEA Pharma Systems AG, Aeromatic-Fielder, Bubendorf, Switzerland). The inlet 
temperature. product temperature and outlet temperature were 58.48 and $45^{\circ} \mathrm{C}$. respectivelv. The target Journal Pre-proofs

weight gain for all formulations was $7 \% \mathrm{w} / \mathrm{w}$. In order to assess the impact of polymer blends (Alg:Pec) ratio on the coating gastro resistance properties, the same coating method was repeated using the following Alg:Pec ratios: 100:0, 85:15, 30:70, 50:50 or 0:100 and 0.5 g of GMS (GMS: polymers ratio 1:16). In order to assess the impact of GMS: polymers mixture ratio, the same above-mentioned method was repeated using identical $8 \mathrm{~g}$ of Alg:Pec ratio 85:15 and increasing amounts of GMS (i.e. 0.5, 4 and $8 \mathrm{~g})$ to achieve GMS: polymer mixture ratios of 1:16, 1:2 and 1:1 w/w, respectively.

\subsection{Morphology of casted and coated films}

Coating appearance was examined by capturing side-by-side digital images of coated and uncoated tablets using Canon EOS Rebel SL1 Digital SLR camera (model DS126441). To examine the coating thickness and morphology, cross-sectioned, undusted tablets were observed using JCM-6000 plus NeoScope ${ }^{\mathrm{TM}}$ microscope (Jeol, Tokyo, Japan) at $10 \mathrm{kV}$. All samples were gold coated using a JFC-1200 Fine Coater (Jeol, Tokyo, Japan). The images were collected using Image J software version 1.2.0. (Tokyo, Japan).

\subsection{Disintegration and water-uptake tests}

The disintegration test was performed in accordance with United Stated Pharmacopeia 30 (USP30) standards using ZT 122 (Erweka, Germany) disintegration apparatus. Briefly, one tablet was placed in each vessel that contained $800 \mathrm{~mL}$ of gastric medium and the apparatus was operated at 30 cycles per minute and $37 \pm 2{ }^{\circ} \mathrm{C}$ for 1 hour. The medium was then replaced with $800 \mathrm{~mL}$ of intestinal medium and the test was continued until the complete disintegration of all tablets.

For the water-uptake test, the original weights $(\mathrm{OW})$ of tablets coated with film containing increased ratio of GMS ( $0: 16$ to $4: 16)$ were accurately measured. One tablet was placed in the vessel of the dissolution tester containing $900 \mathrm{~mL}$ of gastric medium and the apparatus was operated at $37^{\circ} \mathrm{C}$ and 50 rpm. After 2 hours, tablets were collected, the water drops on the surface of tablets were removed, and 
the tablets wet weights (WW) were measured. The percentage water uptake by the coated core was Journal Pre-proofs

calculated according to Eq. 1.

\subsection{Theophylline dissolution and release study}

The in-vitro theophylline dissolution from coated tablets was performed using an AT7 Smart dissolution USP II apparatus (Sotax, Switzerland) set at a temperature of $37 \pm 0.5^{\circ} \mathrm{C}$ and a stirring rate of $50 \mathrm{rpm}$. At first, one coated tablet was placed in $750 \mathrm{~mL}$ of gastric medium for 2 hours. Subsequently, the $\mathrm{pH}$ of the dissolution medium was raised to 6.8 by the adding $250 \mathrm{~mL}$ of $0.214 \mathrm{M}$ tribasic phosphate and the dissolution test was continued for additional 2 hours. The amount of released theophylline was determined at 5 min intervals using a UV/VIS spectrophotometer (PG Instruments Limited, UK) at the wavelength of $272 \mathrm{~nm}$ and path length of $1 \mathrm{~mm}$.

\subsection{Stability Studies}

The tablets coated with (Alg:Pec 85:15): GMS 16:1 were placed in HDPE bottles at $40{ }^{\circ} \mathrm{C} 75 \% \mathrm{RH}$ in a humidity controlled incubator. The samples were tested for water uptake, disintegration time, and dissolution and release profiles according to the methods detailed above following production and after 1,3 and 6 months.

\subsection{Statistical analysis}

Statistical significance was determined using the one-way analysis of variance (ANOVA) and Student's $t$-tests as appropriate. All experiments were performed in triplicate and values were expressed as the mean \pm standard deviation. Values of $p<0.05$ were considered statistically significant. 


\subsection{Water uptake and weight loss studies of casted films}

\section{- $\quad$ GMS-free cast films:}

Gravimetric analysis successfully recorded the water uptake and the weight loss percentages of the GMS-free cast films in gastric medium (Fig. 1). The films exhibited instant and considerable water uptake, irrespective to the Alg-Pec ratio, with an equilibrium of approximately $300 \%$ reached after one hour of incubation (Fig 1.a). This observation is in a good accordance with a previous report (Sriamornsak and Kennedy, 2008). The water uptake by films was also associated with significant weight loss in the range of 25 to $35 \%$ (Fig 1.c). However, the differences in water uptake and in weight loss percentages were negligible across the four investigated polymers blend ratios. Both Alg and Pec are naturally-occurring linear polysaccharides that are widely used in both pharmaceutical and food industries. While Alg is composed of (1-4)- $\beta$-d-mannuronic acid (1-4)- $\alpha$-1-guluronic acid units, Pec is a partially methylated ester made of (1-4)- $\alpha$-d-galacturonic acid interrupted with (1-2)- $\alpha$-1-rhamnose, amongst other neutral sugar units (Dalaty et al., 2016; Sriamornsak, 2003; Sriamornsak and Kennedy, 2008). When dissolved in water, both Alg and Pec behave as hydrophilic weak acids with pKa values falling in the range of 3.4 to 4.5 (Barbosa et al., 2019; Khoder et al., 2009; Sriamornsak, 2003). Therefore, they do not undergo significant ionisation ( $\mathrm{pKa}-\mathrm{pH}>2)$ in acidic medium (Dalaty et al., 2016). Consequently, films based on $\mathrm{Alg} / \mathrm{Pec}$ blends did not dissolve in the gastric medium. However, owing to their hydrophilic nature, the films demonstrated a high wettability and adsorbed significant amounts of the medium. Furthermore, polysaccharides are prone to significant acidic hydrolysis (Kang et al., 2012), which is considered as a first-step toward the film erosion and disintegration. This might contribute to the significant weight loss of the films in the gastric medium. 

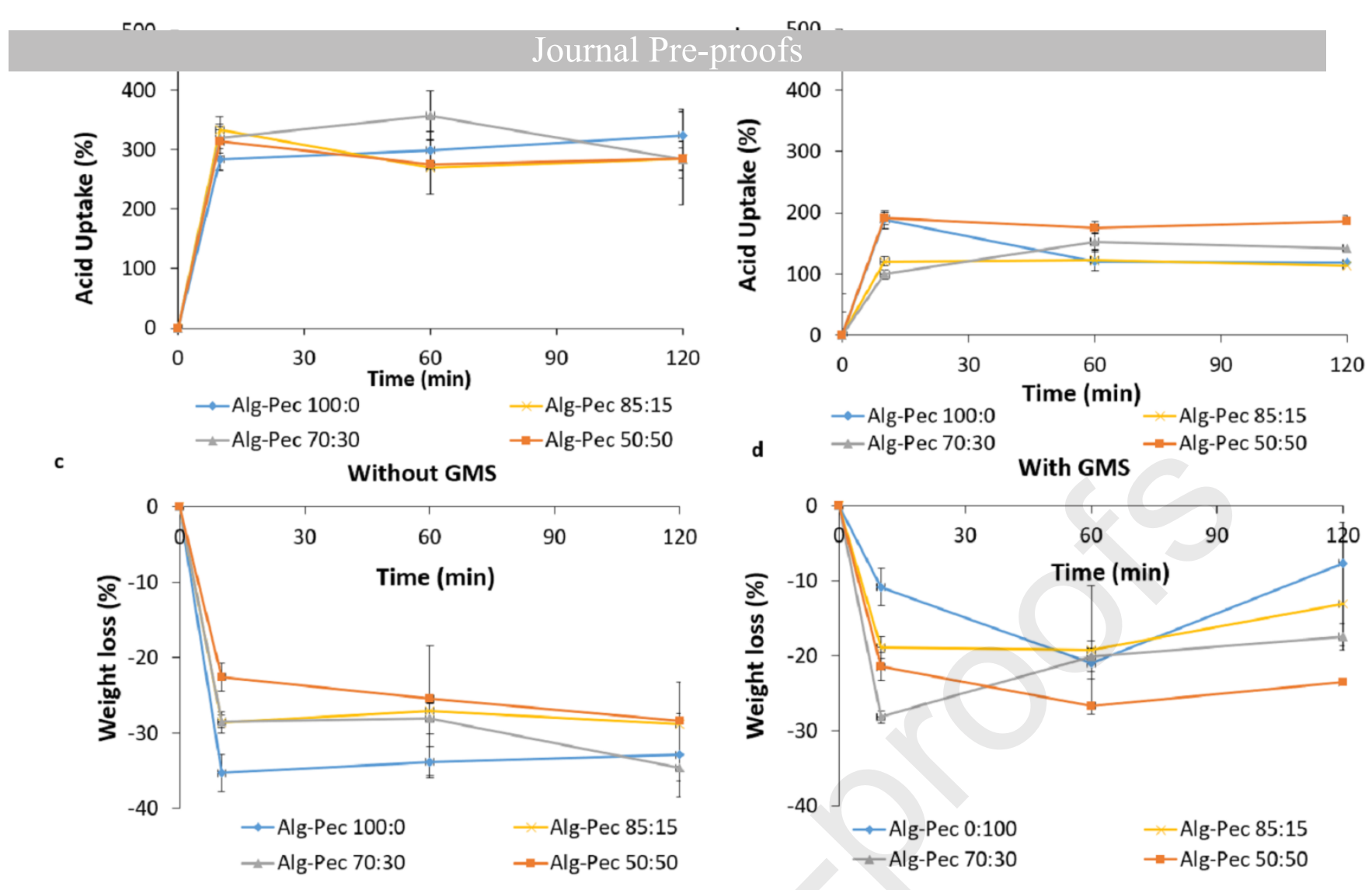

Fig. 1 Impact of Alg-Pec blends ratio and the GMS inclusion (GMS:polymer 1:16) on the cast films water uptake and weight loss in GM: (a) water uptake without GMS, (b) water uptake with GMS, (c) weight loss without GMS, and (d) weight loss with GMS (Mean $\pm \mathrm{SD}, \mathrm{n}=4$ ).

\section{- GMS-containing cast films}

Interestingly, the inclusion of GMS into the polymer blends (GMS: Polymers ratio 1:16) reduced significantly both water uptake (down to $200 \%$ ) and weight loss $(<30 \%)$ of all the formulations. The Alg-Pec blend of a ratio of 85:15 displayed the lowest water uptake and weight loss, $120 \%$ and $25 \%$, respectively, that were reached after 10 min of incubation in the gastric medium (Fig. 1.b). Heating and maintaining the solution temperature above the GMS melting point was needed to homogeneously mix it with water. The DSC and TGA thermograms of Alg, Pec, GMS, as well as Alg:Pec (85:15) films are shown in Fig. 2. The DSC thermograms of Alg, Pec and their GMS-free films do not exhibit any exothermic peak during the course of DSC test (i.e. temperature increased up to $150^{\circ} \mathrm{C}$ ), suggesting the amorphous nature of polymers and their thermal stability at the film casting temperature $\left(70{ }^{\circ} \mathrm{C}\right)$. However, DSC thermogram of GMS displayed a sharp endothermic peak at $65^{\circ} \mathrm{C}$ (Fig. 2.b), which 
films, indicating the presence of GMS particles in the film structure.
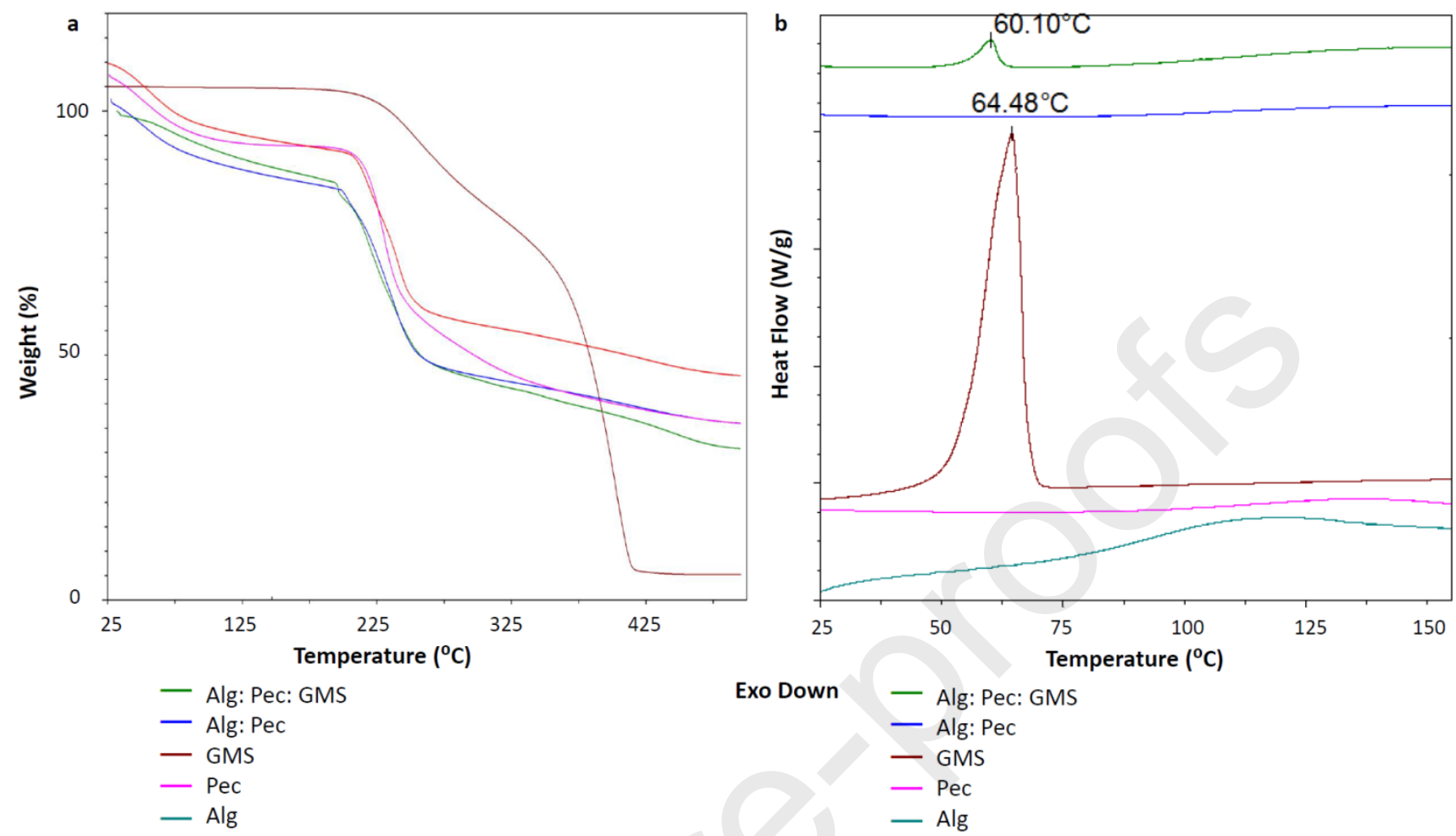

Fig. 2 (a) TGA and (b) DSC thermograms of Alg, Pec, GMS, and Alg:Pec (85:15) cast films with and without GMS (GMS: polymers 1:16)

Indeed, the enhanced gastric resistance of the generated films after the inclusion of GMS could be attributed to their relatively hydrophobic properties that might lower the overall hydrophilic nature of obtained films. As a result, the overall wettability of the obtained films will be reduced. The fact that the DSC thermograph of GMS-containing film displayed its melting point peak might suggest the formation of GMS pockets within the polysaccharide matrices. However, increasing GMS ratios in the polysaccharide blends did not lead to further lowering in the weight loss nor in the water uptake (data not shown).

In order to gain a better understanding of the role of GMS during the film formation process, GMS: AlgPec (1:16) dispersion was heated in an open DSC pan and observed under the digital microscope (Fig. 3a). As the dispersion is heated to $70^{\circ} \mathrm{C}$, an obvious change in the clarity of the liquid was observed. The cross marked at the bottom of the pan became more visible as the liquid became clearer. There was 
also clear evidence of the film beginning to form at the edges of the DSC pan. The normalised heat flow Journal Pre-proofs

from the DSC showed a curving baseline as a result of the water evaporation from the pan during the heating experiment. This could not be avoided as the lid of the DSC pan had to be removed to allow observation by the camera. However, the first derivative of the heat flow indicated an onset temperature of approximately $60^{\circ} \mathrm{C}$. This confirms the melting transition observed by conventional DSC in the preformed film. Light microscopy showed the formation of droplets of an approximate diameter range of 10-60 $\mu \mathrm{m}$ (Fig. 3b); upon cooling these droplets turned into solid particles of similar size range.
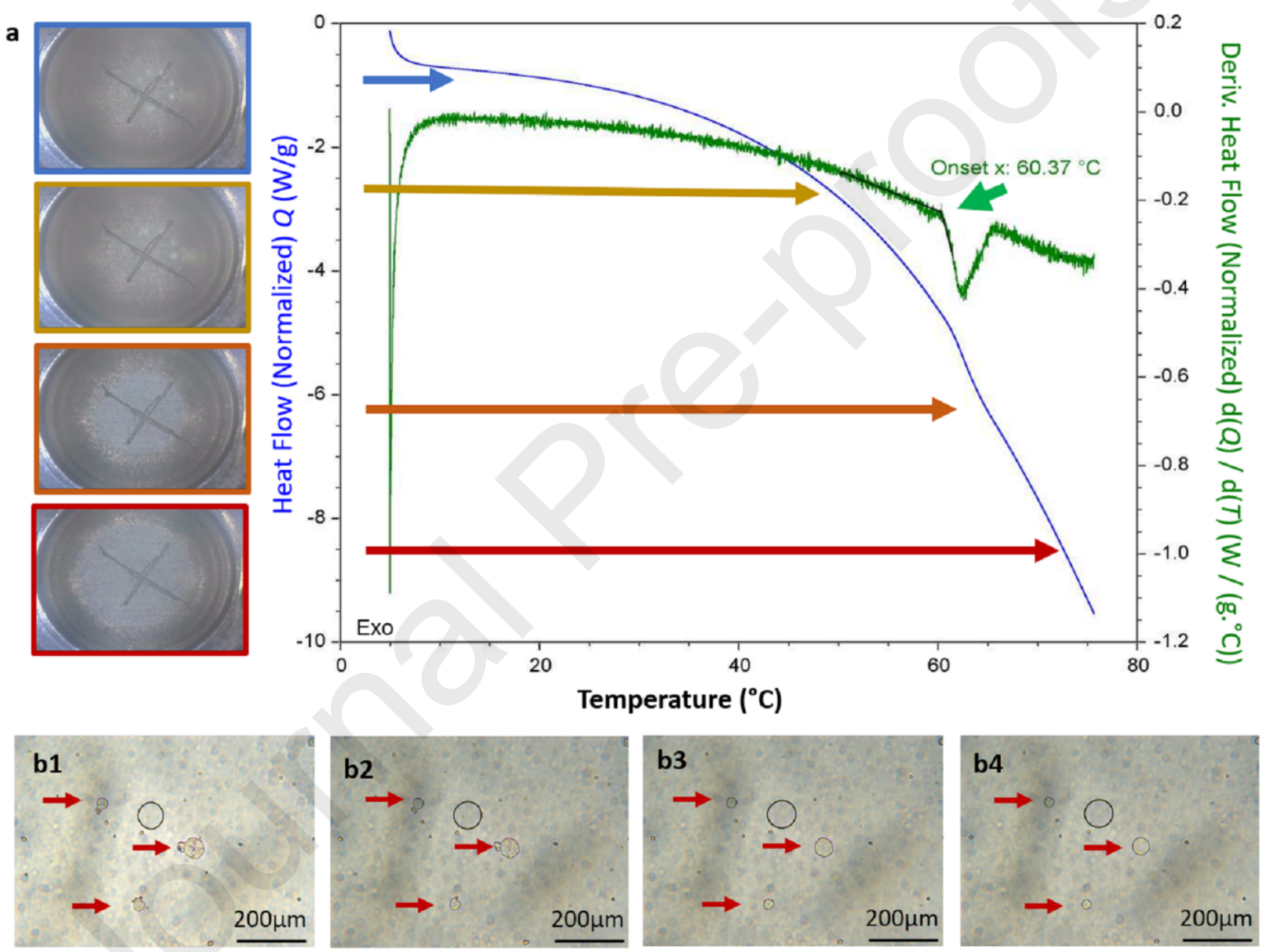

Fig. 3 (a) DSC thermogram of coating dispersion liquid (GMS: Polymer 1:16), blue line: normalised heat flow, green line: the first derivative of the heat flow, and corresponding images of the sample. Light microscopic images of the coating dispersion as it cools from (b1) $75^{\circ} \mathrm{C}$ to (b2) 60 , (b3) 45 and (b4) $25^{\circ} \mathrm{C}$.

GMS is a surfactant with a hydrophilic-lipophilic balance (HLB) of 3-4 (Azizi and Rao, 2005). During water evaporation and as the film is being formed on the surface of the core, the concentration of GMS (initial concentration $\left.=7 \times 10^{-3} \mathrm{~mol} \cdot \mathrm{dm}^{-3}\right)$ will increase above the critical micelles concentration $(\mathrm{CMC}$ $=4.50 \times 10^{-2} \mathrm{~mol} \cdot \mathrm{dm}^{-3}$ (Chidi and Adebayo, 2018)). Further drying might lead to the condensation of 
the GMS lavers adsorbed at the interphases and the merge of the formed micelles (Pantoia-Romero et Journal Pre-proofs

al., 2016). The merging of the formed micelles may have led to the formation of oil droplets that made the diffusion path more tortuous. This could explain the significant enhancement of overall hydrophobic behaviour of the film.

\subsection{Coated theophylline tablets}

\section{- Preliminary coating study}

In order to assess the impact of GMS on the coated film properties, a control GMS-free Alg-Pec (Alg:Pec 85:85) blend was firstly applied to coat the model core, using a fluidised bed coater. However, the coating produced by GMS-free blend disintegrated within $30 \mathrm{~min}$ in acidic medium and resulted in a premature and complete release of theophylline (Fig.4). As this might be attributed to the lack of plasticity of the applied film, the Alg-Pec blend was plasticised using PEG 6000, a commonly used plasticiser and film former, at a PEG 6000: polymers ratio of 1:16 and similar results were obtained (Fig.4). Indeed, this property has allowed alginate to be used as a natural coating for immediate release products (Rajsharad and Kamble, 2006).

Interestingly, when GMS was incorporated in the film formulation, at the same ratio of the plasticizer used above, the tablet showed gastro-resistant properties for 2 hours (Fig. 3). This confirms the findings of the cast film and highlights the drastic and positive impact of this naturally occurring hydrophobic surfactant on the film functionality. 


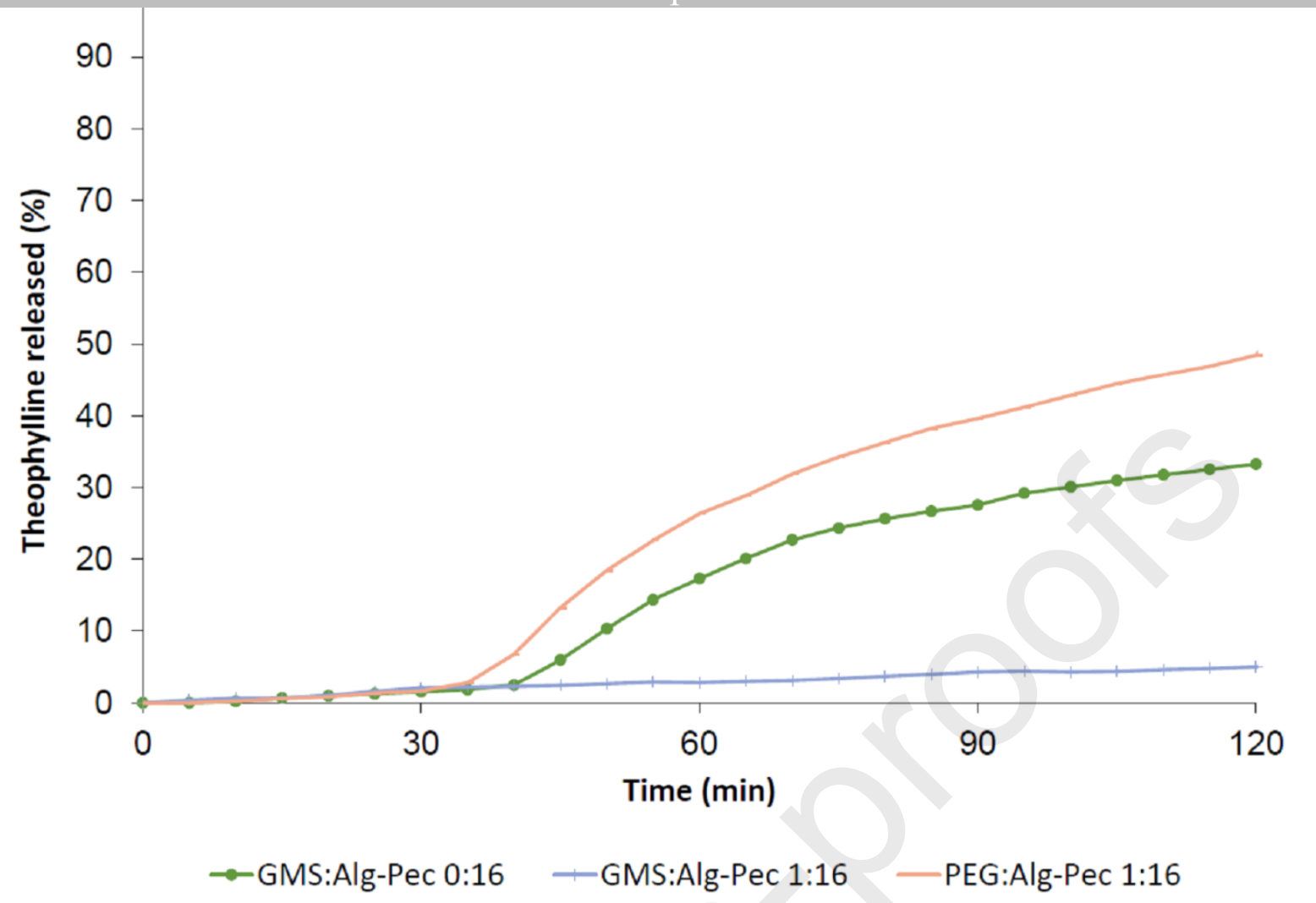

Fig. 4 Theophylline release (\%) from tablet coated with Alg:Pec (85:15) with no additive, with GMS or with hydrophilic plasticiser (PEG 6000) in gastric medium ( $\mathrm{pH}$ 1.2) (additive: polymers 1:16) in gastric medium (Mean $\pm \mathrm{SD}, \mathrm{n}=3$ ).

Owing to their good film-forming properties, Alg and Pec have been traditionally used to prepare pharmaceutical films and coatings (Macleod et al., 1999; Pereira et al., 2011; Rhim, 2004; Sriamornsak and Kennedy, 2008). Propylene glycol alginate (partially esterified with 1,2-propandiol) has been used as semi-synthesised coating due to its film forming properties and $\mathrm{pH}$-responsive behaviour (Siepmann et al., 2008a; Siepmann et al., 2008c). However, to the authors' knowledge, none of these unmodified polysaccharides has been used for enteric coating. Even though both Alg and Pec do not dissolve in acidic media, they are not expected to possess any gastro-resistance properties due to the water uptake capability and the subsequent permeability and potential acidic hydrolysis under such harsh acid condition. This was also confirmed in the cast film results reported here. GMS appeared to transform the gastric resistance of the coating films and therefore might impact on the resulting coating film properties in a similar way when included in the cast films. The adsorption of GMS molecules at the liquid-air interface of the individual droplets of sprayed polymeric solutions could likewise take place during the coating process that might result in a significant increase in the overall hydrophobic nature 
of the tablet surface. This can lead to enhanced gastro-resistant properties of the film coating. Based on Journal Pre-proofs

these promising preliminary results, the impact of the GMS on polysaccharides-based coating films was studied in detail where the effect of both GMS concentration and the polymers blends ratio were investigated.

\section{- Enteric coating properties of GMS-containing films}

Theophylline tablets following coating with Alg-Pec blends with GMS were captured by photography and scanning electron microscopy (Fig. 5; GMS: polymer 18:85). All GMS-containing Alg-Pec blends generated continuous, smooth and flawless coating layers of yellow tinge colour. Coating films displayed enhanced smoothness as the pectin ratio increases compared to films based on Alg only. The SEM images of a cross-session of the coated tablets illustrate the formation of a smooth and consistent film structure with an approximate thickness of $80 \mu \mathrm{m}$ (Fig. 5).
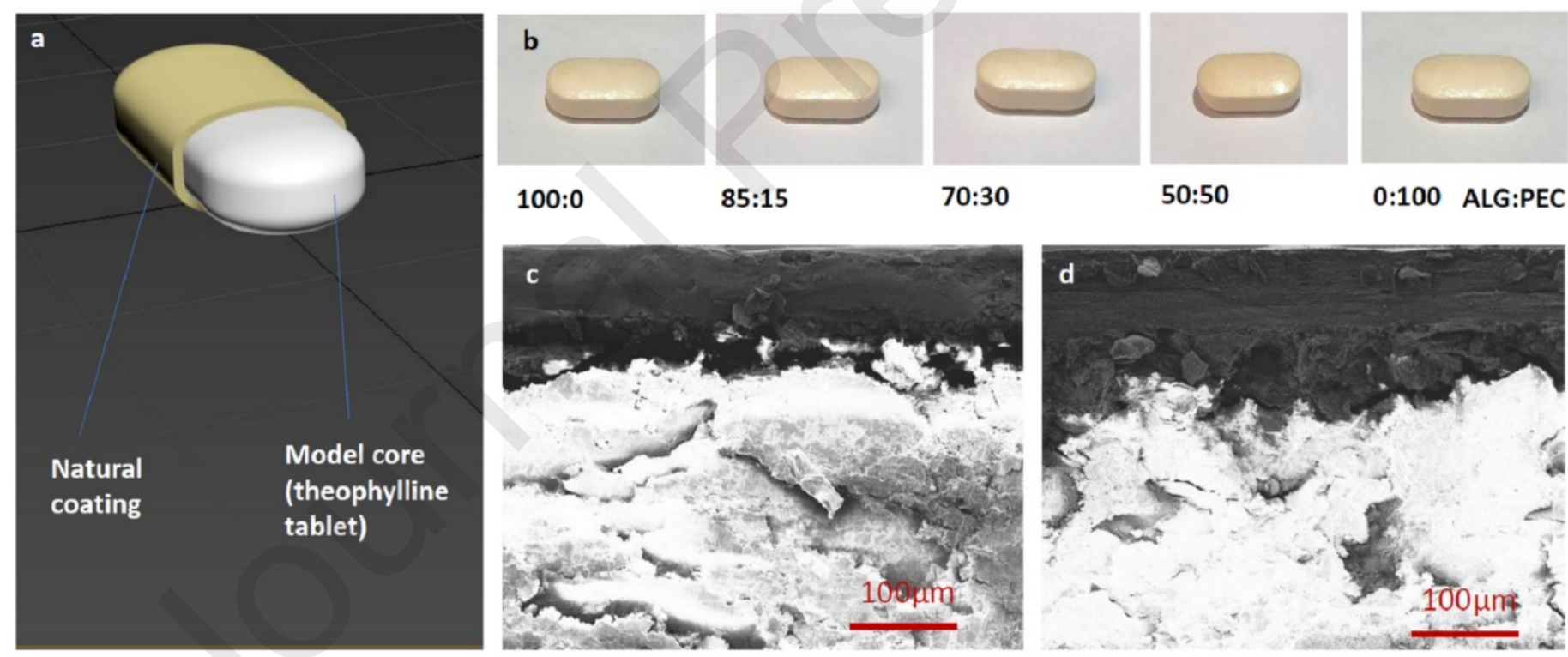

Fig. 5 (a) Illustrative virtual image of theophylline coated tablet, (b) actual photographs of coated theophylline tablets coated with Alg:Pec blends (100:0, 85:15, 70:30, 50:50 or 0:100) blends with GMS (GMS: polymers 1:16). SEM images of a cross-section of theophylline tablet coated with Alg:Pec (85:15) (c) without GMS or (d) with 1:16 (GMS: polymer), respectively.

The disintegration times of the enteric coated (all with GMS) theophylline tablets were assessed according to the (USP30) pharmacopoeia standards. While tablets coated with a film made of Pec (AlgPec 00:100) were not stable in the gastric medium, those coated with pure Alg (Alg-Pec 100:00) or Alg- 
Pec blends (Alg-Pec 85:15. 70:30. and 50:50) successfully sustained 1-hour exposure in the gastric phase Journal Pre-proofs

followed by a complete disintegration in less than $10 \mathrm{~min}$ ) when the intestinal medium was added into the disintegration test (Table 1). This was confirmed by pH-change pharmacopeial dissolution study; all GMS containing films, except those made of Pec, inhibited the release within the first 2 hours $(<5 \%$ released) in the gastric phase and immediately and completely released the drug in the intestinal phase (Fig. 6.a). This conforms to the compendial expectations of delayed release formulations. To the authors' knowledge, this is the first report of alginate-based coating system that achieves such gastro-resistant properties without the inclusion of synthetic or semi-synthetic additives.

Table 1: The disintegration time (min) of theophylline tablets coated with different Alg:Pec blend ratios with GMS (GMS: polymer 1:16) and with different GMS: polymers ratio (Alg:Pec 85:15).

\begin{tabular}{lll}
\hline Film & Status after 1 hour $(\mathbf{p H ~ 1 . 2 )}$ & $\begin{array}{l}\text { Simulated intestinal fluid } \\
(\mathbf{p H ~ 7 . 4 )}\end{array}$ \\
\hline Alg:Pec 00:100* & Broken & - \\
Alg:Pec 100:0* & Stable & $9 \mathrm{~min}$ \\
Alg:Pec 85:15* & Stable & $9 \mathrm{~min}$ \\
Alg:Pec 70:30* & Stable & $7 \mathrm{~min}$ \\
Alg:Pec 50:50* & Stable & $6 \mathrm{~min}$ \\
\hline GMS:Alg-Pec 0:16 & Broken & - \\
GMS:Alg-Pec 1:16 & Stable & $13 \mathrm{~min}$ \\
GMS:Alg-Pec 1:8 & Stable & $10 \mathrm{~min}$ \\
GMS:Alg-Pec 1:4 & Stable & $10 \mathrm{~min}$ \\
GMS:Alg-Pec 1:2 & Stable & $10 \mathrm{~min}$ \\
GMS:Alg-Pec 1:1 & Broken & - \\
\hline
\end{tabular}

* GMS: Polymers ratio 1:16

To evaluate the impact of GMS content of the films on their gastric resistance properties, tablets were coated with different GMS: polymer ratios. The absence of GMS in blend film led to the disintegration of the coated tablets within the first $30 \mathrm{~min}$ of the test (Table 1). The inclusion of GMS in the film formulation (GMS: polymers 1:16 to 8:16) resulted in gastro-resistant coating films that are compatible with USP criterion of disintegration of delayed release products. However, further increase in GMS contents (i.e. GMS: polymers 1:1) led to a compromised gastro-resistance. In a good accordance with the disintegration data, increasing the GMS ratio was also associated with a progressive and significant decrease in the percentages of the water taken up by the tablet during the incubation in the gastric 
medium. While GMS-free coated tablets underwent considerable and fast water uptake and subsequently Journal Pre-proofs

completely disintegration in the gastric medium, those containing GMS within the coating layer demonstrated reduced weight gain (from $35 \%$ to $25 \%$ when the GMS: polymer ratio was increased from 01:16 to $04: 16$ ), allowing the protection of the tablets structure in the GM.

The pKa values of Alg and Pec are 3.37 and 3.45 respectively (Barbosa et al., 2019). At low pH (pKa $\mathrm{pH}>2$ ), the ionisation of both polysaccharides would be minimal resulting in their precipitation. Although the precipitation of polymers could prevent the drug release in the gastric medium, these polymers, without the addition of GMS, were not able to prevent/reduce the water uptake in the GM, hence the complete disintegration of tablets in this medium. Increasing the $\mathrm{pH}$ of the dissolution medium to the ionisation level of $\mathrm{Alg}$ and $\mathrm{Pec}$ (i.e. $\mathrm{pH}>3.5$ ) is expected to initiate the polymers ionisation and dissolution. This was clearly demonstrated in the prompt response in the drug release following $\mathrm{pH}$ change. However, this has also yielded limited gastro-resistant properties at elevated gastric $\mathrm{pH}$ (Supplementary Data Fig. S1). Improving the performance of the coating system in the fed state conditions (i.e. $\mathrm{pH} 2-5$ ) is the subject of future investigations.

In addition to its role as hydrophobic enhancer properties discussed above, the GMS is predicted to play a plasticising role in the film formulation. Plasticisers weaken the intramolecular bonds between the film forming polymers chains, hence they enhance the elastic properties of the resultant film (Vieira et al., 2011). In contrast, a high concentration of a plasticiser has the potential to cause phase separation within the coating. Furthermore, high ratios of GMS, for example 1:1, would be expected to weaken the integrity of the film structure to an extent that it could not withstand the mechanical pressure of the expanding core following water imbibition (Yang and Paulson, 2000).

The in-vitro dissolution and release profiles of theophylline from tablets coated with Alg:Pect (85:15) film containing increased content of GMS were recorded whilst a step change in the $\mathrm{pH}$ was applied after two hours (Fig. 6.b). Film containing GMS at ratios ranging from 1:16 to 4:16 conformed to the USP delayed release specifications (i.e. less than $10 \%$ in the first 2 hours in acid followed by over $85 \%$ released after $45 \mathrm{~min}$ in the intestinal phase). A further increase in the GMS ratio (GMS: polymers 8:16) 
slowed down the drug release in the intestinal phase. This mav be interpreted as a consequence of the Journal Pre-proofs

increased hydrophobicity of the film matrix. Such a mechanism has been reported to sustain the drug release (Hiew et al., 2019) and this will impact on the bioavailability of some delayed release preparation. In a good accordance to the findings of disintegration tests, GMS rich structure (GMS ratio 16:16) broke within the first 10 min of the introduction to acidic medium and led to premature drug release. This highlights the suitability of the system to delay drug release and the potential for further improvements in gastric protection properties. Interestingly, the stability studies of a selected enteric coated theophylline tablet (Alg:Pec 85:15 blend with GMS: polymers 1:16) revealed that the functionality of the coating layer was maintained for up to six months under accelerated conditions. Fig. 7 shows the dissolution profiles of theophylline from the above mentioned enteric coated tablets after 0 , 1, 3 and 6 months of incubation in stability cabinet with no significant difference observed comparing to the control dissolution profile (i.e. 0 month).

Fig. 6: The impact of (a) the Alg:Pec ratio on the theophylline release (GMS: polymers ratio 1:16) and (b) the impact of the GMS: polymers ratio (Alg:Pec 85:15) on the theophylline release. (USP II dissolution test, $\mathrm{pH}-$
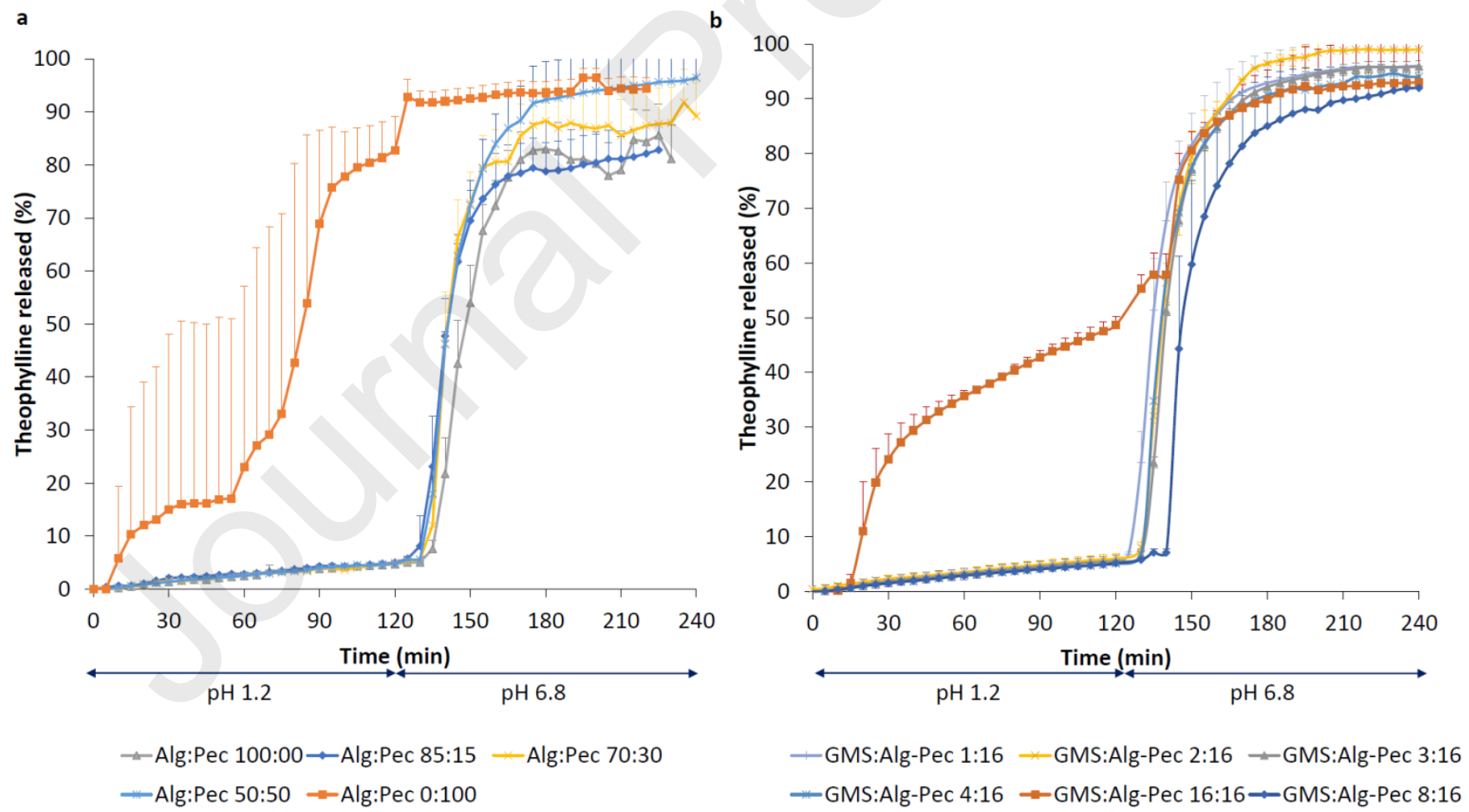
change method $\mathrm{pH} 1.2$ for 2 hours followed by $\mathrm{pH} 6.8$, Mean $\pm \mathrm{SD}, \mathrm{n}=3$ ). 


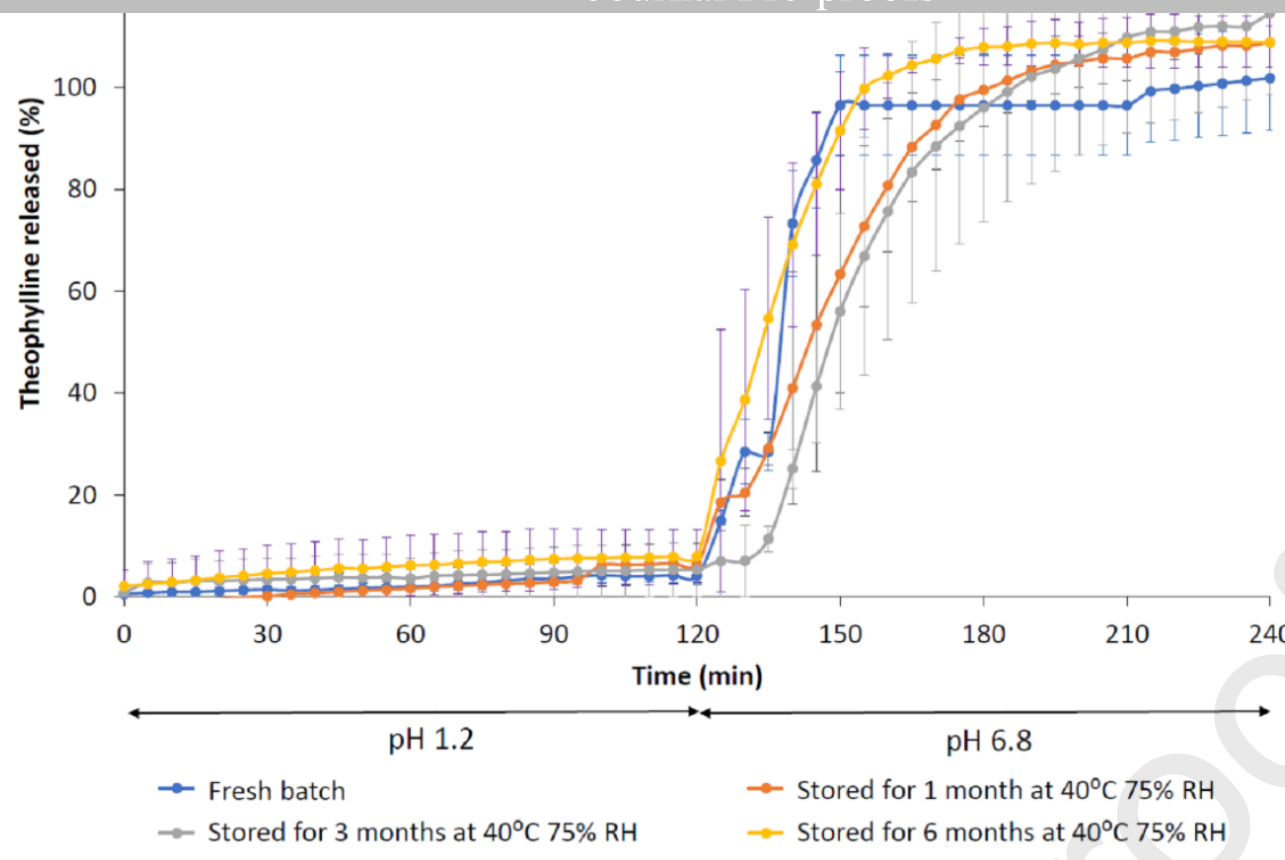

Fig. 7: Theophylline release from tablet coated with Alg: Pec blend (Alg:Pec 85:15) with GMS (GMS: polymer 1:16) using $\mathrm{pH}$-change method (USP II dissolution test: $\mathrm{pH} 1.2$ for 2 hours followed by $\mathrm{pH} 6.8$ ) following 0,1 , 3,6 months storage at $75 \% \mathrm{RH}$ and $40 \mathrm{oC}$. (Mean $\pm \mathrm{SD}, \mathrm{n}=3$ ).

Being natural polymers, both Alg and Pec have inherited variability that restricts their application for enteric coating (Barbosa et al., 2017). Including GMS within the coating formulations is potentially a viable approach to overcome this limitation and allow the production of more consistent, reproducible and stable enteric coating.

\section{Conclusion}

We have reported for the first time the impact of including a naturally occurring hydrophobic surfactant (GMS) on the gastro-resistant properties of alginate polymer. GMS: polysaccharides blend ratios 1:168:16 appeared to render the film gastro-resistant and pass pharmacopeial criteria for delayed release formulation. The incorporation of pectin into the film system improved the appearance of the coating without significantly impacting the gastric resistance properties. The coating system remained gastroresistant under accelerated stability conditions. These findings are of a particular importance for nutraceutical industry, where the delayed release of natural products is often achieved by the undesired use of synthetized or semi-synthetized polymers-based coating systems. 
Azizi, M.H., Rao, G.V., 2005. Effect of surfactant in pasting characteristics of various starches. Food Hydrocolloids 19, 739-743.

Barbosa, J.A.C., Abdelsadig, M.S.E., Conway, B.R., Merchant, H.A., 2019. Using zeta potential to study the ionisation behaviour of polymers employed in modified-release dosage forms and estimating their pKa. International Journal of Pharmaceutics: X 1, 100024.

Barbosa, J.A.C., Conway, B.R., Merchant, H., 2017. Going natural: using polymers from nature for gastroresistant applications. British Journal of Pharmacy.

Chidi, O., Adebayo, I., 2018. Determination of Critical Micelle Concentration and Thermodynamic Evaluations of Micellization of GMS. Mod Chem Appl 6, 2.

Czarnocka, J.K., Alhnan, M.A., 2015. Gastro-resistant characteristics of GRAS-grade enteric coatings for pharmaceutical and nutraceutical products. International Journal of Pharmaceutics 486, 167-174.

Dalaty, A.A., Karam, A., Najlah, M., Alany, R.G., Khoder, M., 2016. Effect of non-cross-linked calcium on characteristics, swelling behaviour, drug release and mucoadhesiveness of calcium alginate beads.

Carbohydrate Polymers 140, 163-170.

Farag, Y., Leopold, C.S., 2009. Physicochemical Properties of Various Shellac Types. Dissolut Technol 16, 33-39. Hiew, T.N., Tan, D.L.H., Tiang, Y.L., Heng, P.W.S., 2019. Understanding the release performance of pellets with hydrophobic inclusions in sustained-release coating. International Journal of Pharmaceutics 557, 229-237. Hoffmann, E.M., Breitenbach, A., Breitkreutz, J., 2011. Advances in orodispersible films for drug delivery. Expert Opin Drug Deliv 8, 299-316.

Kang, E.-k., Lee, B.M., Hwang, H.A., Kim, J.-H., 2012. Analysis of mono-sugars obtained by acid hydrolysis of algae-based polysaccharides. Journal of Industrial and Engineering Chemistry 18, 1366-1369.

Khoder, M., Tsapis, N., Fattal, E., 2010. Mechanisms of antibiotic resistance and delivery strategies to prevent its emergence. Journal of Drug Delivery Science and Technology 20, 407-418.

Khoder, M., Tsapis, N., Huguet, H., Besnard, M., Gueutin, C., Fattal, E., 2009. Removal of ciprofloxacin in simulated digestive media by activated charcoal entrapped within zinc-pectinate beads. International Journal of Pharmaceutics 379, 251-259.

Lecomte, F., Siepmann, J., Walther, M., MacRae, R.J., Bodmeier, R., 2003. Blends of enteric and GIT-insoluble polymers used for film coating: physicochemical characterization and drug release patterns. Journal of Controlled Release 89, 457-471.

Lecomte, F., Siepmann, J., Walther, M., MacRae, R.J., Bodmeier, R., 2004. Polymer Blends Used for the Coating of Multiparticulates: Comparison of Aqueous and Organic Coating Techniques. Pharmaceutical Research 21, 882-890.

Limmatvapirat, S., Nunthanid, J., Luangtana-anan, M., Puttipipatkhachorn, S., 2005. Effect of alkali treatment on properties of native shellac and stability of hydrolyzed shellac. Pharm Dev Technol 10, 41-46.

Macleod, G.S., Collett, J.H., Fell, J.T., 1999. The potential use of mixed films of pectin, chitosan and HPMC for bimodal drug release. Journal of Controlled Release 58, 303-310.

Maderuelo, C., Lanao, J.M., Zarzuelo, A., 2019. Enteric coating of oral solid dosage forms as a tool to improve drug bioavailability. European Journal of Pharmaceutical Sciences 138, 105019.

Martini, L.G., Crowley, P.J., 2011. Controlling Drug Release in Oral Product Development Programs: An Industrial Perspective, in: Wilson, C.G., Crowley, P.J. (Eds.), Controlled Release in Oral Drug Delivery. Springer US, Boston, MA, pp. 49-69.

Pantoja-Romero, W.S., Estrada-López, E.D., Picciani, P.H.S., Oliveira, O.N., Lachter, E.R., Pimentel, A.S., 2016. Efficient molecular packing of glycerol monostearate in Langmuir monolayers at the air-water interface.

Colloids and Surfaces A: Physicochemical and Engineering Aspects 508, 85-92.

Pearnchob, N., Siepmann, J., Bodmeier, R., 2003. Pharmaceutical Applications of Shellac: Moisture-Protective and Taste-Masking Coatings and Extended-Release Matrix Tablets. Drug Development and Industrial Pharmacy 29, 925-938.

Pereira, R., Tojeira, A., Vaz, D.C., Mendes, A., Bártolo, P., 2011. Preparation and Characterization of Films Based on Alginate and Aloe Vera. International Journal of Polymer Analysis and Characterization 16, 449-464.

Rajsharad, C., Kamble, S., 2006. Aqueous film coating composition containing sodium alginate and preparation.

Research, G.V., 2019. Nutraceuticals Market Worth $\$ 578.23$ Billion By 2025, https://www.grandviewresearch.com/press-release/global-nutraceuticals-market (last accessed 30 Sep 2019). 
Siegel, R.A., Rathbone, M.J., 2012. Overview of Controlled Release Mechanisms, in: Siepmann, J., Siegel, R.A., Rathbone, M.J. (Eds.), Fundamentals and Applications of Controlled Release Drug Delivery. Springer US, Boston, MA, pp. 19-43.

Siepmann, F., Muschert, S., Leclercq, B., Carlin, B., Siepmann, J., 2008a. How to improve the storage stability of aqueous polymeric film coatings. Journal of Controlled Release 126, 26-33.

Siepmann, F., Siepmann, J., Walther, M., MacRae, R.J., Bodmeier, R., 2008b. Polymer blends for controlled release coatings. Journal of Controlled Release 125, 1-15.

Siepmann, F., Wahle, C., Leclercq, B., Carlin, B., Siepmann, J., 2008c. pH-sensitive film coatings: Towards a better understanding and facilitated optimization. European Journal of Pharmaceutics and Biopharmaceutics 68, 2-10.

Sriamornsak, P., 2003. Chemistry of pectin and its pharmaceutical uses: A review. Silpakorn University International Journal 3, 206-228.

Sriamornsak, P., Kennedy, R.A., 2008. Swelling and diffusion studies of calcium polysaccharide gels intended for film coating. International Journal of Pharmaceutics 358, 205-213.

Theismann, E.M., Keppler, J.K., Knipp, J.R., Fangmann, D., Appel, E., Gorb, S.N., Waetzig, G.H., Schreiber, S., Laudes, M., Schwarz, K., 2019. Adjustment of triple shellac coating for precise release of bioactive substances with different physico-chemical properties in the ileocolonic region. Int J Pharm 564, 472-484.

Vieira, M.G.A., da Silva, M.A., dos Santos, L.O., Beppu, M.M., 2011. Natural-based plasticizers and biopolymer films: A review. European Polymer Journal 47, 254-263.

Wang, F.C., Peyronel, F., Marangoni, A.G., 2016. Phase Diagram of Glycerol Monostearate and Sodium Stearoyl Lactylate. Crystal Growth \& Design 16, 297-306.

Yang, L., Paulson, A.T., 2000. Mechanical and water vapour barrier properties of edible gellan films. Food Research International 33, 563-570. 

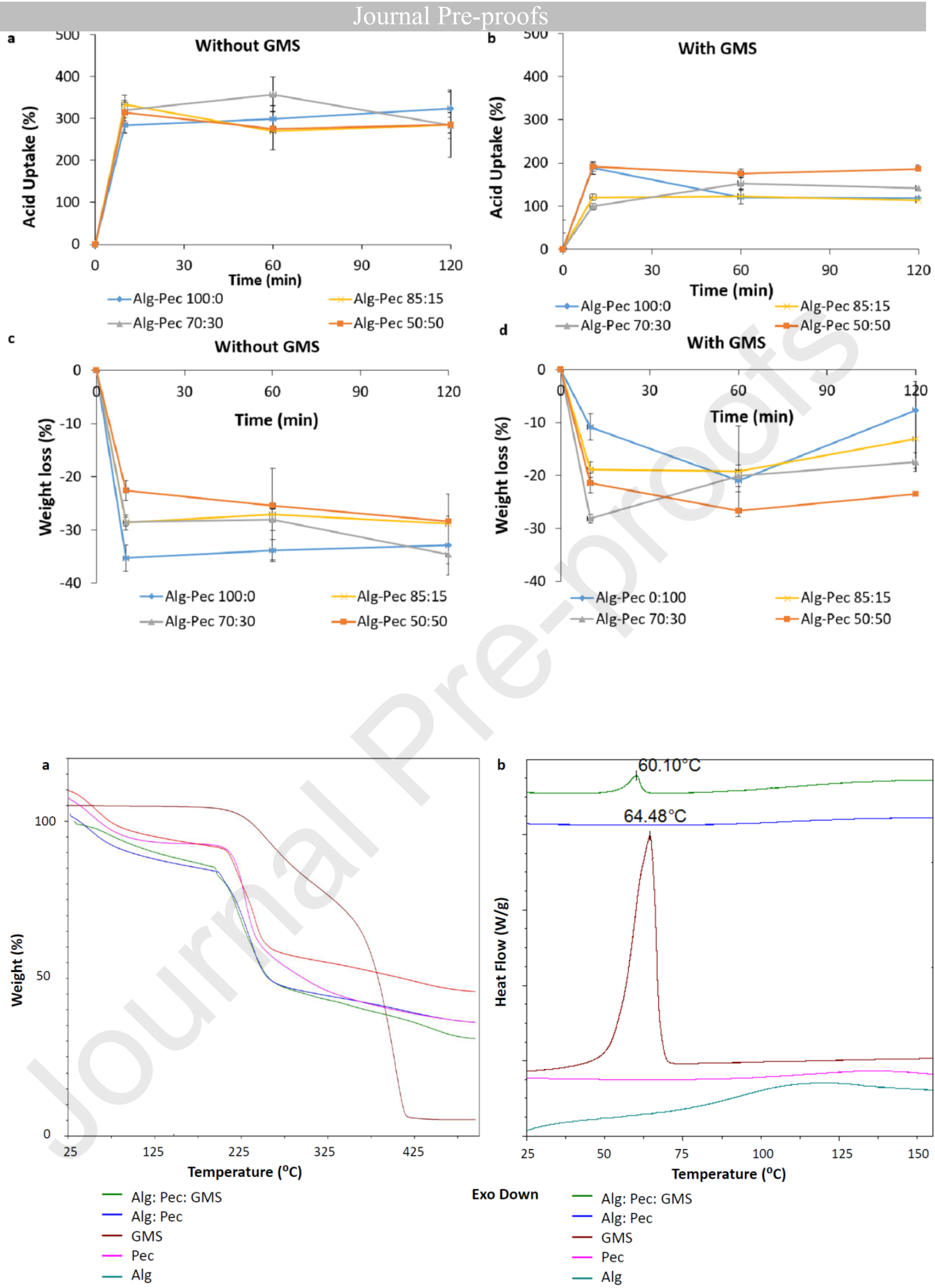
a

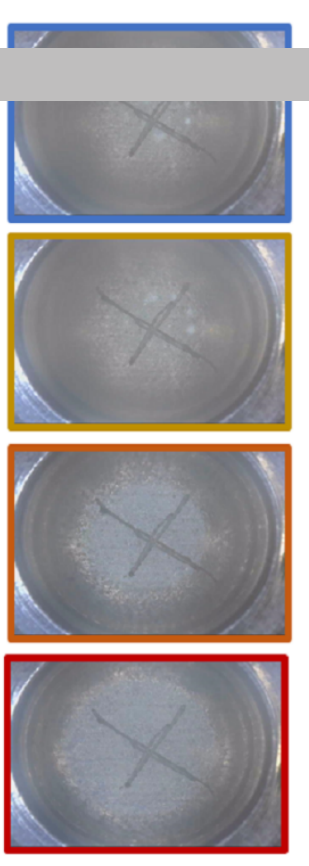

Toumal Pre-proofs

0.2
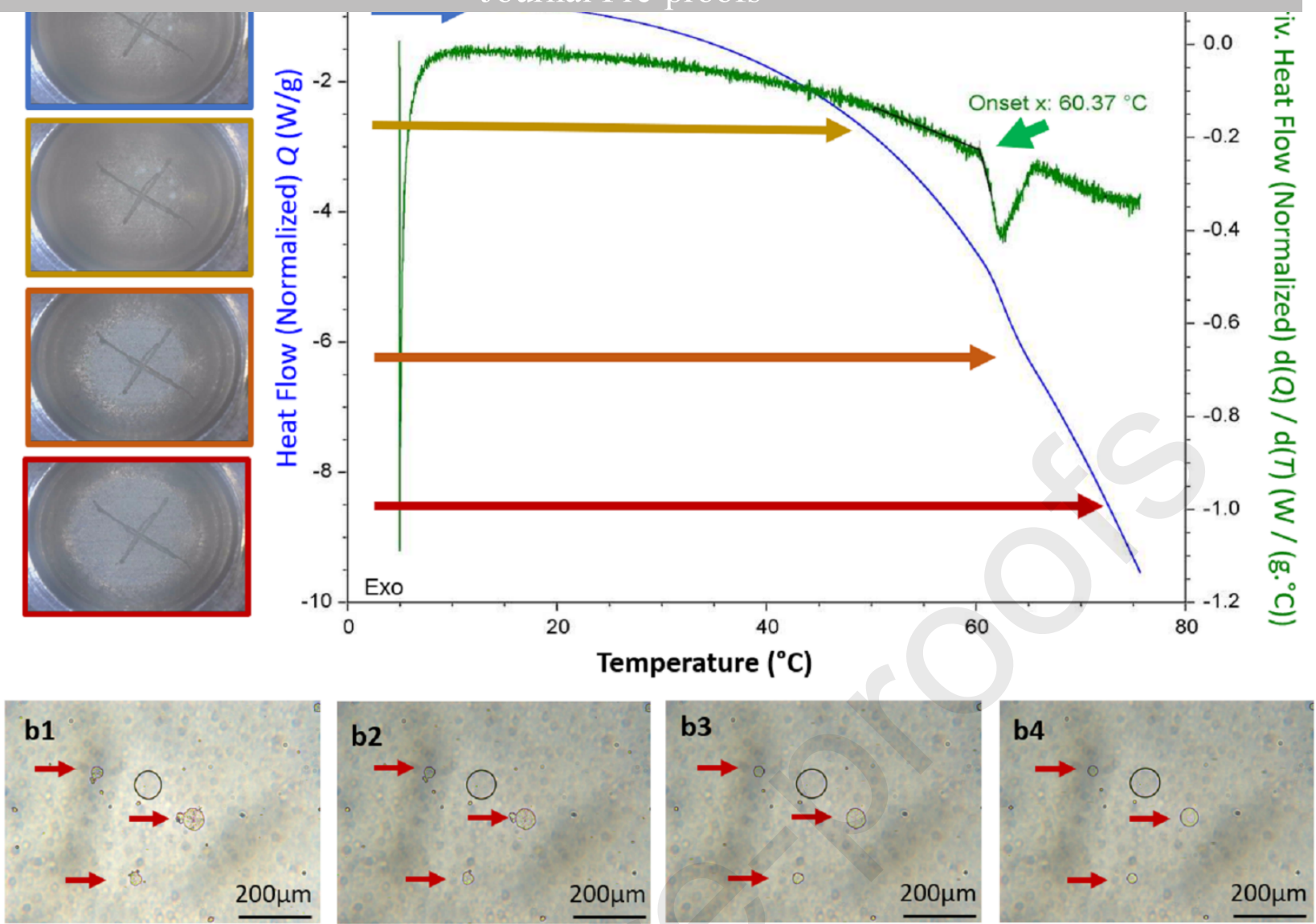

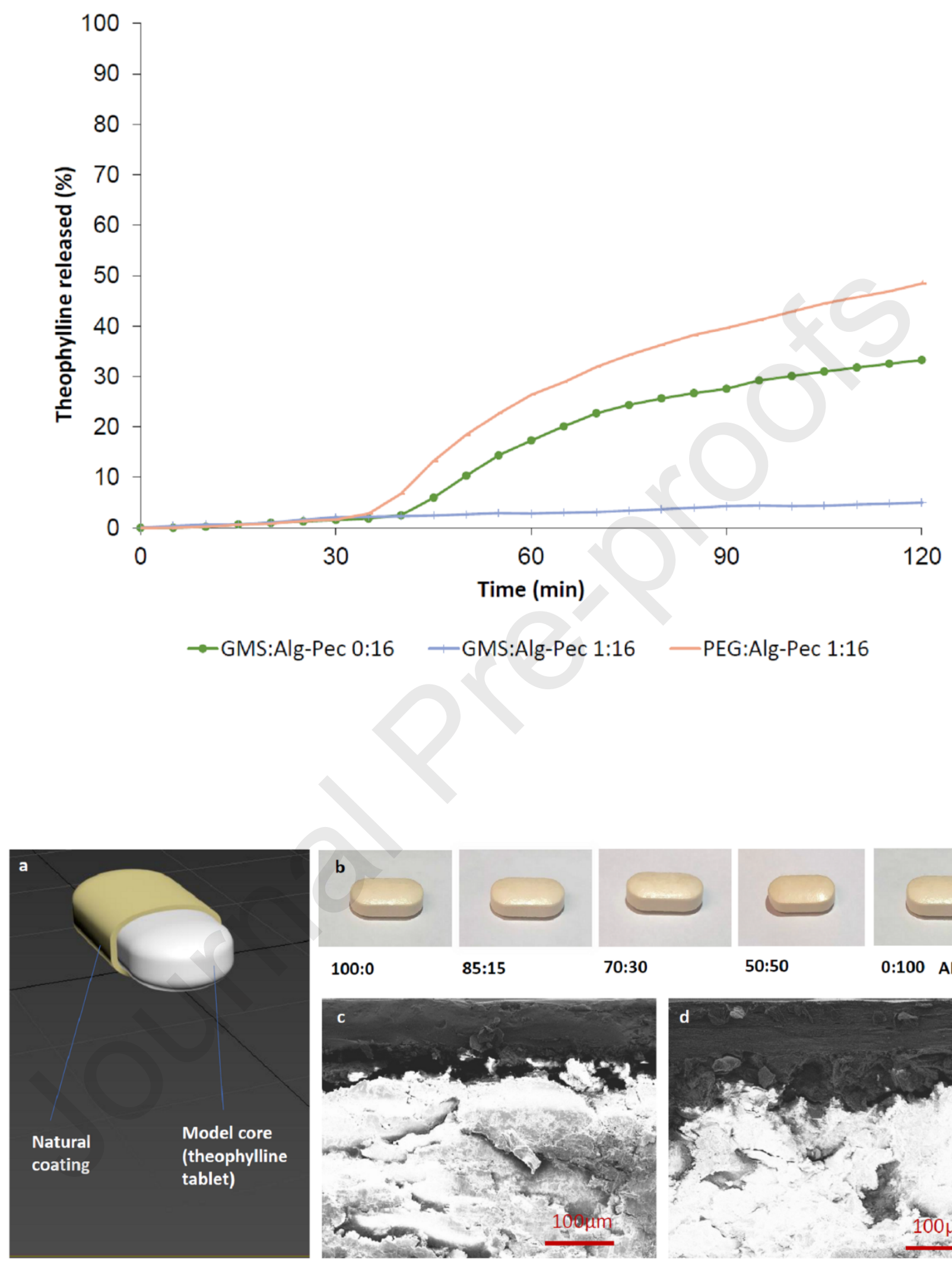

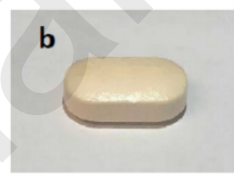

100:0

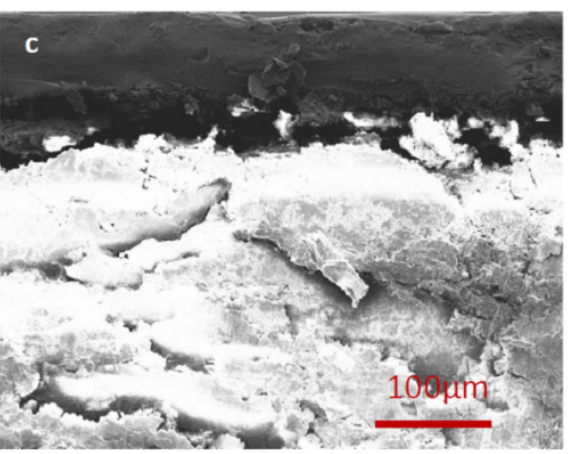

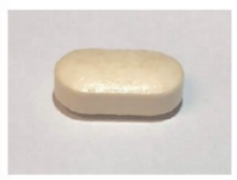

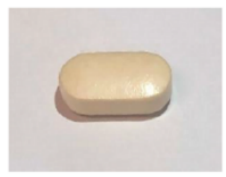

50:50

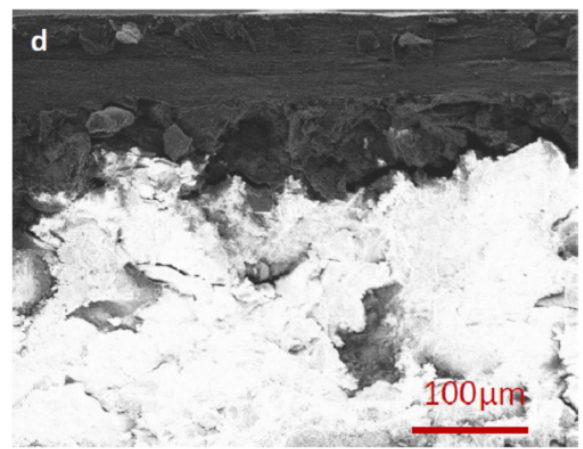


$h$

\section{Journal Pre-proofs}
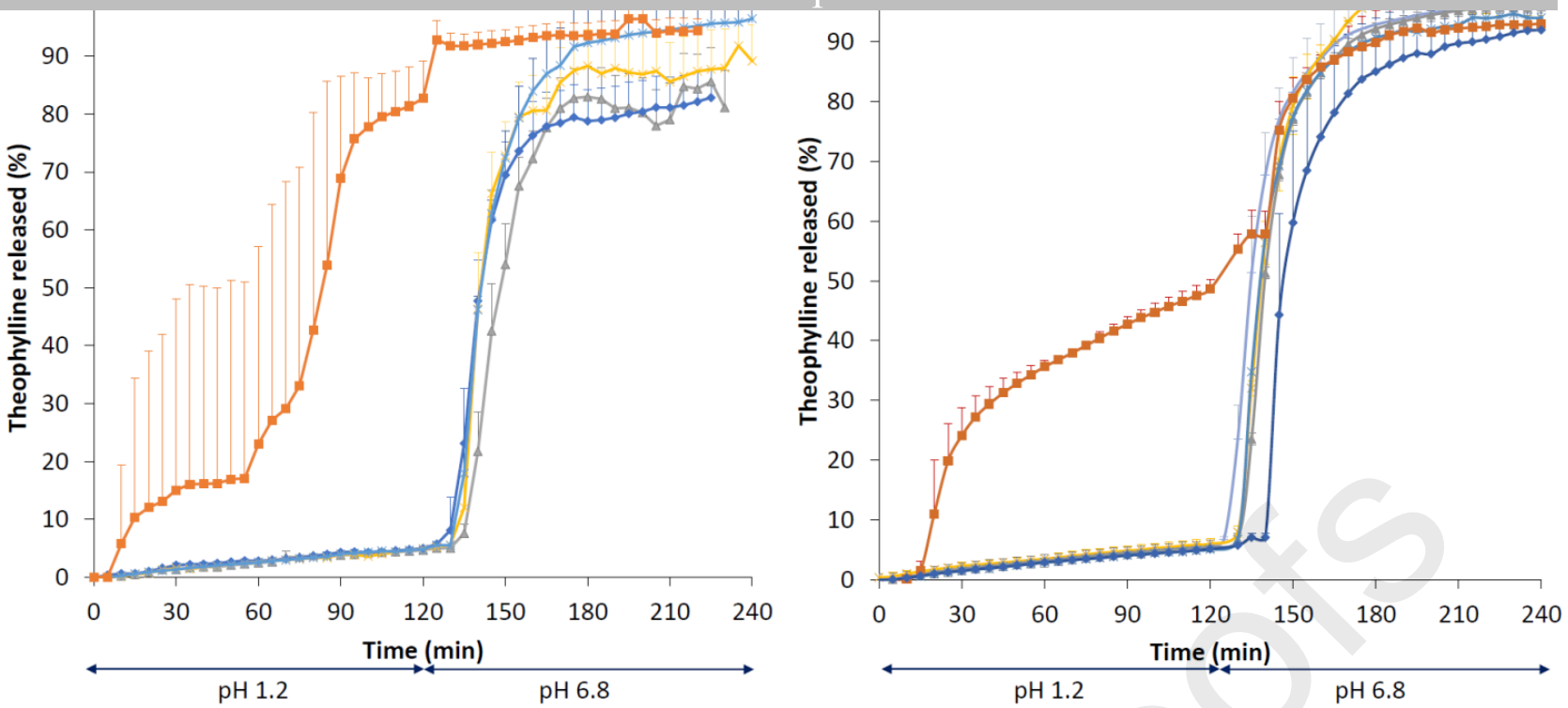

$\leadsto$ Alg:Pec 100:00 —Alg:Pec 85:15 —Alg:Pec 70:30

—GMS:Alg-Pec 1:16 —GMS:Alg-Pec 2:16 —GMS:Alg-Pec 3:16

—Alg:Pec 50:50 -Alg:Pec 0:100

—GMS:Alg-Pec 4:16 —GMS:Alg-Pec 16:16 -GMS:Alg-Pec 8:16 


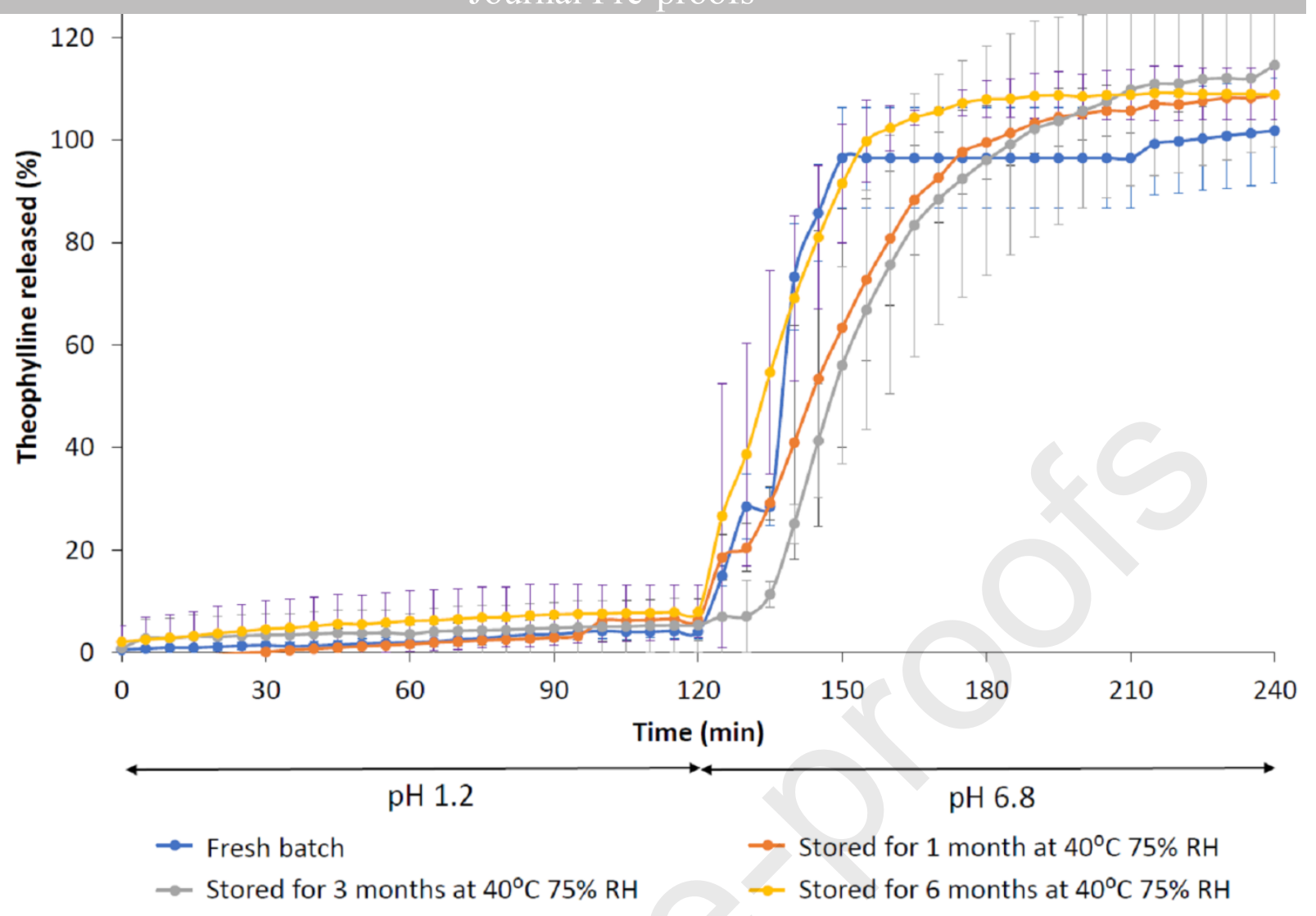

Table 1: The disintegration time ( $\mathrm{min}$ ) in GM of theophylline tablets coated with differen Alg:Pec blend ratios with GMS (GMS: polymer 1:16) and with different GMS: polymers ratio (Alg:Pec 85:15).

\begin{tabular}{lll}
\hline Film & $\begin{array}{l}\text { Status after 1 hour } \\
\text { (pH 1.2) }\end{array}$ & $\begin{array}{l}\text { Simulated intestinal } \\
\text { fluid (pH 7.4) }\end{array}$ \\
\hline Alg:Pec 00:100* & Broke & - \\
Alg:Pec 100:0* & Stable & $9 \mathrm{~min}$ \\
Alg:Pec 85:15* & Stable & $9 \mathrm{~min}$ \\
Alg:Pec 70:30* & Stable & $7 \mathrm{~min}$ \\
Alg:Pec 50:50* & Stable & $6 \mathrm{~min}$ \\
\hline GMS:Alg-Pec 0:16 & Broke & - \\
GMS:Alg-Pec 1:16 & stable & $13 \mathrm{~min}$ \\
GMS:Alg-Pec 1:8 & stable & $10 \mathrm{~min}$ \\
GMS:Alg-Pec 1:4 & stable & $10 \mathrm{~min}$ \\
GMS:Alg-Pec 1:2 & stable & $10 \mathrm{~min}$ \\
GMS:Alg-Pec 1:1 & broke & - \\
\hline
\end{tabular}

* GMS: Polymers ratio 1:16 
M A Alhnan: Conceptualization, Methodology, Visualization Software; Writing- Reviewing and Editing, Supervision; M Khoder: Writing- Original draft preparation, and-Reviewing; R Habashy, B Preira, S Zeitler \& V Schropp; Investigation. P Royall \& J Wang: Methodology and Visualization 


\section{Declaration of interests}

Journal Pre-proofs

$\bigotimes$ The authors declare that they have no known competing financial interests or personal relationships that could have appeared to influence the work reported in this paper.

$\square$ The authors declare the following financial interests/personal relationships which may be considered as potential competing interests:

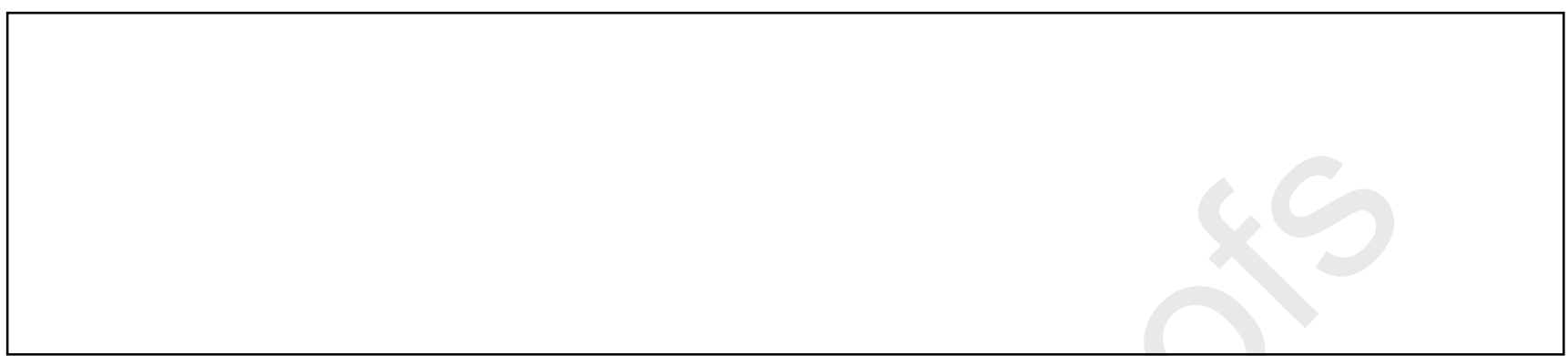




\section{Journal Pre-proofs}

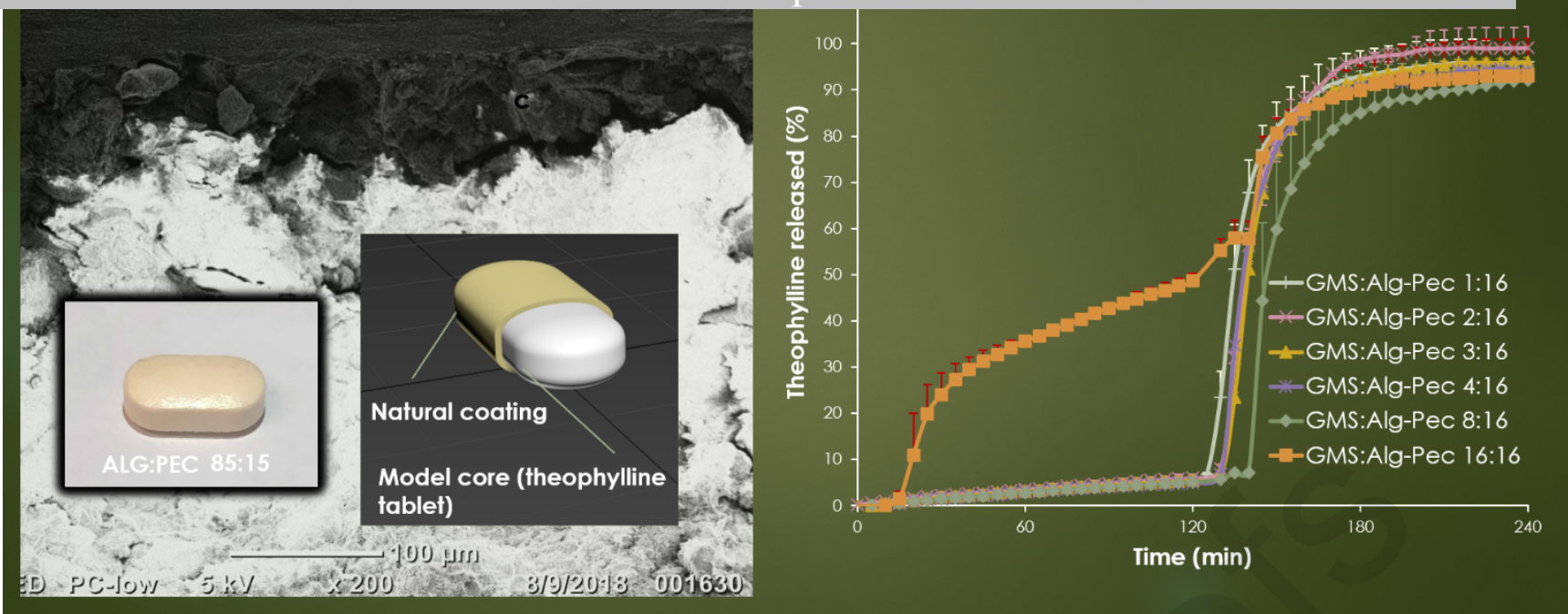

